\title{
Anti-Markovnikov Hydroamination of Alkenes with Aqueous Ammonia by Metal-Loaded Titanium Oxide Photocatalyst
}

\section{AUTHOR(S):}

Park, Soyeong; Jeong, Jaeyoung; Fujita, Ken-ichi; Yamamoto, Akira; Yoshida, Hisao

\section{CITATION:}

Park, Soyeong ... [et al]. Anti-Markovnikov Hydroamination of Alkenes with Aqueous Ammonia by Metal-Loaded Titanium Oxide Photocatalyst. Journal of the American Chemical Society 2020, 142(29): 12708-12714

\section{ISSUE DATE:}

2020-07-22

URL:

http://hdl.handle.net/2433/253574

\section{RIGHT:}

This document is the Accepted Manuscript version of a Published Work that appeared in final form in 'Journal of the American Chemical Society', copyright (c) American Chemical Society after peer review and technical editing by the publisher. To access the final edited and published work see https://doi.org/10.1021/jacs.0c04598.; The full-text file wil be made open to the public on 22 June 2021 in accordance with publisher's 'Terms and Conditions for Self-Archiving'; This is not the published version. Please cite only the published version.; この論文は出版社版でありません。引用の際 には出版社版をご確認ご利用ください。 


\title{
Anti-Markovnikov hydroamination of alkenes with aqueous ammo- nia by metal-loaded titanium oxide photocatalyst
}

\author{
Soyeong Park ${ }^{\dagger}$, Jaeyoung Jeong ${ }^{\dagger}$, Ken-ichi Fujita ${ }^{\dagger}$, Akira Yamamoto $^{\dagger, \neq} \&$ Hisao Yoshida ${ }^{\dagger, \neq *}$
}

\begin{abstract}
A completely new route was established to synthesize valuable primary amines from alkenes by using aqueous ammonia, that is, a simple photocatalytic hydroamination of alkenes using aqueous ammonia with a metal-loaded $\mathrm{TiO}_{2}$ photocatalyst. Although the photochemical hydroamination prefers to form amines according to Markovnikov rule, the new photocatalytic hydroamination gives anti-Markovnikov products predominantly. With an Au-loaded $\mathrm{TiO}_{2}$ photocatalyst, the amine yield reached up to $93 \%$ and the regioselectivity of anti-Markovnikov products was above $98 \%$. The reaction mechanism was proposed for the new photocatalytic hydroamination.
\end{abstract}

\section{INTRODUCTION}

Amines are greatly important compounds as intermediates in chemical industry to produce dyes, agricultural pesticides, and pharmaceuticals. Especially, primary and secondary amines are important, because which have access to biologically active materials and more generally fine chemicals. ${ }^{1}$ While the synthesis of secondary amines has been studied by homogeneous catalysts, it is very difficult to apply these catalysts for the synthesis of primary amines. Accordingly, more efficient synthetic method of amines has been always required, and the development of catalytic processes for nitrogen based molecule has attracted much attention. Especially, catalytic hydroamination of olefins and alkynes is quite attractive due to the simplicity and the high atom efficiency. ${ }^{2}$

Catalytic hydroamination of olefins to yield secondary amines have been intensively studied, where an amine reacts with the unsaturated $\mathrm{C}=\mathrm{C}$ bond to form a new $\mathrm{C}-\mathrm{NHR}$ and $\mathrm{C}-\mathrm{H}$ bonds giving an aimed amine, either inter- or intramolecular amine and the regioselectivity of amine usually follows Markovnikov rule (Scheme 1) ${ }^{3-9}$ On the other hand, only several studies have also been reported on hydroamination providing anti-Markovnikov products with metal complex catalysts have also been reported. ${ }^{10-20}$ However, hydroamination to form primary amine has never been reported. In the present study, we examined and succeeded in the synthesis of primary amine via hydroamination using aqueous ammonia with photocatalysis (Scheme 2).

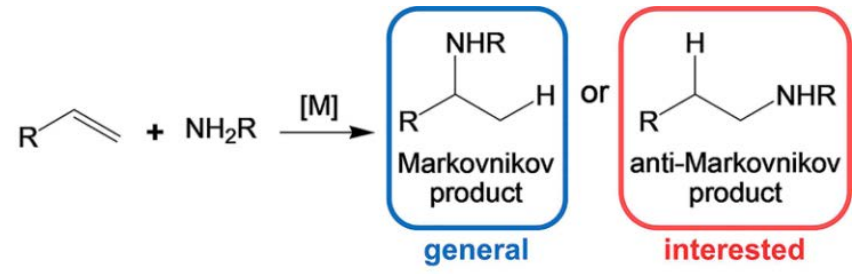

Scheme 1. The synthesis of secondary amines via hydroamination of alkenes with amine by metal complex catalysts

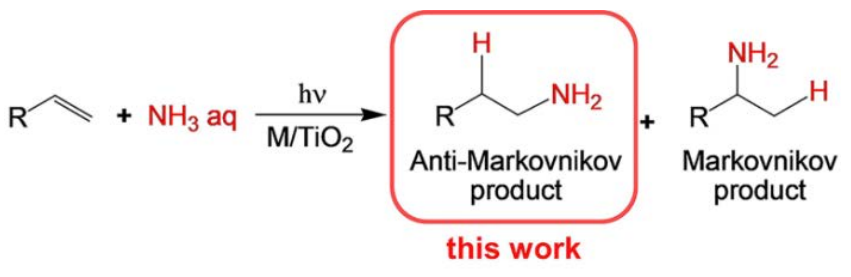

Scheme 2. Photocatalytic hydroamination of alkenes with aqueous ammonia to form primary amines with anti-Markovnikov regioselectivity

\section{RESULTS AND DISCUSSION}

Hydroamination of alkene with ammonia. The heterogeneous photocatalytic reaction test was carried out between alkene (3-buten-1-ylbenzene, 1a) and aqueous ammonia in acetonitrile with $\mathrm{a}^{\mathrm{TiO}}$ 2 photocatalyst under photoirradiation for $3 \mathrm{~h}$ (Table 1, entry 1), which predominantly gave a primary amine (4-phenyl-1-butanamine, 2a) as an antiMarkovnikov product. On the other hand, in the photochemical reaction without any photocatalyst, only another primary amine as a Markovnikov product (4-phenyl-2-butanamine, 3a) was detected (Table 1, entry 2). The opposite regioselectivity of primary amine originates from different reaction mechanisms, as discussed later.

In the photocatalytic hydroamination, the yield of amine was significantly increased by loading $0.1 \mathrm{wt} \%$ of metal cocatalysts such as $\mathrm{Au}, \mathrm{Pt}$, and $\mathrm{Pd}$ on the $\mathrm{TiO}_{2}$ photocatalyst (Table 1, entries 3-5, $\left.\mathrm{M}(0.1) / \mathrm{TiO}_{2}\right)$. Photoexcitation of $\mathrm{TiO}_{2}$ produces electron-hole $\left(\mathrm{e}^{-}-\mathrm{h}^{+}\right)$pairs, and they can react with adsorbed reactant molecules only when they reach to the surface without recombination. ${ }^{21}$ The loaded metal cocatalyst is considered to receive the photoexcited electrons from the conduction band of $\mathrm{TiO}_{2}$ efficiently and reduce the probability of the $\mathrm{e}^{-}-\mathrm{h}^{+}$pairs recombination, ${ }^{22}$ resulting their lifetime extension and thus high photocatalytic performance. 
Table 1. Results of photocatalytic reaction tests for hydroamination of 3-buten-1-ylbenzene (1a)

\begin{tabular}{|c|c|c|c|c|c|c|c|c|}
\hline \multirow{2}{*}{ Entry } & \multirow{2}{*}{ Catalyst } & \multicolumn{3}{|c|}{ Obtained products $/ \mu \mathrm{mol}$} & \multirow{2}{*}{$\begin{array}{c}\text { Conversion }{ }^{c} \\
(\%)\end{array}$} & \multirow{2}{*}{$\begin{array}{l}\text { Yield of amines }{ }^{\mathrm{d}} \\
(\%)\end{array}$} & \multirow{2}{*}{$\begin{array}{l}\text { Selectivity for } \\
\text { amines } \\
(\%)\end{array}$} & \multirow{2}{*}{$\begin{array}{c}\text { Regioselectivity } \\
\text { (\%) }\end{array}$} \\
\hline & & $2 a$ & $3 a$ & Others $^{\mathrm{b}}$ & & & & \\
\hline 1 & $\mathrm{TiO}_{2}$ & 5.63 & - & 2.66 & 0.318 & 0.216 & 67.9 & - \\
\hline 2 & - & - & 1.79 & 1.76 & 0.136 & 0.068 & 50.4 & - \\
\hline 3 & $\mathrm{Au}(0.1) / \mathrm{TiO}_{2}$ & 501 & 10.8 & 42.3 & 21.2 & 19.6 & 92.4 & 97.9 \\
\hline 4 & $\mathrm{Pt}(0.1) / \mathrm{TiO}_{2}$ & 781 & 18.6 & 238 & 39.8 & 30.7 & 77.1 & 97.7 \\
\hline 5 & $\mathrm{Pd}(0.1) / \mathrm{TiO}_{2}$ & 638 & 16.4 & 312 & 37.0 & 25.1 & 67.7 & 97.5 \\
\hline $6^{\mathrm{g}}$ & $\mathrm{Au}(0.1) / \mathrm{TiO}_{2}$ & 14.6 & 0.454 & 10.2 & 1.00 & 0.578 & 57.6 & 97.0 \\
\hline
\end{tabular}

${ }^{\mathrm{a}}$ Catalyst: $150 \mathrm{mg}$; reactants: 3-buten-1-ylbenzene $(0.4 \mathrm{~mL}, 2.61 \mathrm{mmol})$, aqueous ammonia $(28 \%, 1.6 \mathrm{~mL}, 23.7 \mathrm{mmol})$; solvent; acetonitrile (4.0 mL, 73.1 mmol); wavelength of the irradiated light: $\lambda \geq 300 \mathrm{~nm}$; light intensity: $40 \mathrm{~mW} \mathrm{~cm}{ }^{-2}$ measured at $360 \pm 40 \mathrm{~nm}$ in wavelength; reaction time: $3 \mathrm{~h}$; reaction temperature: $303 \mathrm{~K}$; $\mathrm{TiO}_{2}$ used: anatase, $300 \mathrm{~m}^{2} \mathrm{~g}^{-1}$ (ST-01, Ishihara Sangyo Kaisha). ${ }^{\mathrm{b}}$ Others were mainly some bimolecular reaction products from alkene such as 4,5-diphenylocta-1,7-diene and (E)-1,8-diphenyloct-3-ene, the amount of which were tentatively estimated by using the GC-FID calibration curve for trans, trans-1,4-diphenyl-1,3-butadiene, with tiny amounts of unknown products. ${ }^{\mathrm{c} C o n v e r s i o n ~ o f ~ a l k e n e ~(1 a), ~ w h i c h ~ w a s ~ c a l c u l a t e d ~ f r o m ~ t h e ~ i n i t i a l ~ a n d ~ f i n a l ~}$ amounts of 1a. ${ }^{\mathrm{d}}$ Yield of amines (2a and 3a), which was calculated from the initial amount of 1a and the obtained amount of 2a and 3a. ${ }^{\mathrm{e}}$ Selectivity of amine (2a and 3a), which was calculated from the amounts of consumed 1a and obtained 2a and 3a. ${ }^{f}$ Regioselectivity of anti-Markovnikov amine (2a), which was calculated from the amounts of $\mathbf{2 a}$ and 3a obtained. ${ }^{g}$ Water was used as a solvent instead of acetonitrile.

Employing aqueous ammonia in this reaction required a suitable solvent such as acetonitrile, which was crucial to make the liquid phase homogeneous. With the solvent the amines (2a and 3a) were predominantly obtained with the high selectivity such as $92 \%$ (Table 1, entry 3), while without the solvent less amines were obtained with less selectivity (Table 1, entry 6), where the ratio of by-products via bimolecular reaction of alkene was relatively high. Without photoirradiation, no products were formed, indicating that the detected products were formed photocatalytically.

In these photocatalytic conditions, the obtained regioselectivity for the anti-Markovnikov product (2a) was always ca. 97\% (Table 1, entries 3-6). This high regioselectivity will be discussed later.

Proposed mechanism of the photocatalytic hydroamination. Photocatalyst can activate ammonia even in aqueous solution to promote further photocatalytic reactions, e.g., ammonia decomposition ${ }^{23}$ and amination of aromatic ring, ${ }^{24}$ where a photoformed positive hole $\left(\mathrm{h}^{+}\right)$on the photocatalyst surface can oxidize an ammonia molecule to form an amide radical $\left(\cdot \mathrm{NH}_{2}\right)$ and a proton $\left(\mathrm{H}^{+}\right)$and a photoexcited electron reduce a proton to a hydrogen radical $(\cdot \mathrm{H}),{ }^{23}$ followed by the reactions of these radical species with radical species ${ }^{23}$ or molecules. ${ }^{24}$ The photocatalytic generation of the amide radical $\left(\cdot \mathrm{NH}_{2}\right)$ in an aqueous ammonia solution under photoirradiation was clearly evidenced by electron spin resonance (ESR) spectroscopy with a radical trapping reagent in the previous study. ${ }^{24}$

In the present system, these radical species would react with an alkene molecule. Photocatalysis can also promote hydration of alkene with water to give alcohol with predominant selectivity to anti-Markovnikov products, ${ }^{25}$ where a photocatalytically generated active oxygen radical species first reacts with the unsaturated $\mathrm{C}=\mathrm{C}$ bond to form a radical intermediate and the stability of the radical intermediate determines the regioselectivity, i.e., that for anti-Markovnikov product is more stable than that for Markovnikov prod- uct. Theoretical calculation suggested that the possible intermediates of hydrogen radical adducts should be unstable compared to hydroxyl radical adducts. ${ }^{25}$

Considering this mechanism and the present results, the mechanism of the present photocatalytic hydroamination can be analogously proposed as follows (Scheme 3): a photocatalytically formed amide radical first reacts with alkene to form a radical intermediate (amide radical adduct), which reacts with a hydrogen radical to give an anti-Markovnikov product. Other possible intermediates (amide radical adduct for a Markovnikov product and hydrogen radical adducts) would be quite minor.
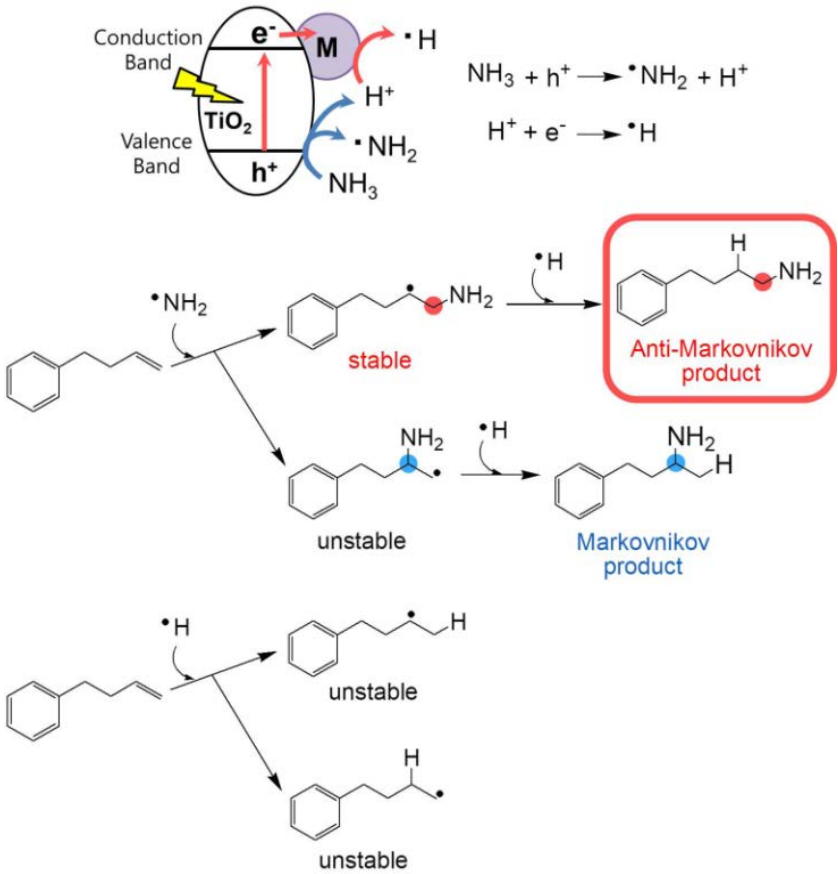

Scheme 3. Proposed mechanism of the new photocatalytic hydroamination 

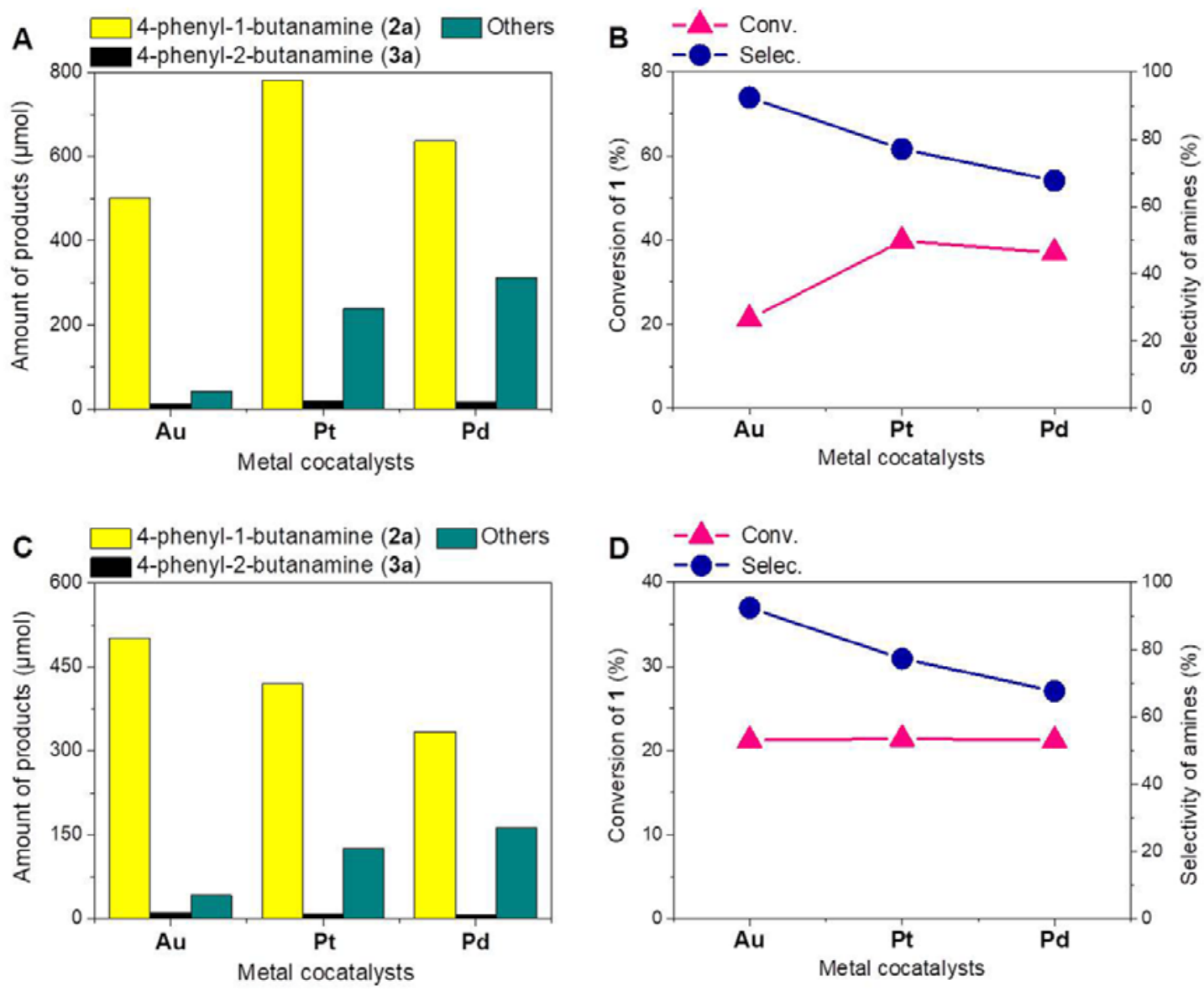

Figure 1. The results of photocatalytic hydroamination of 3-buten-1-ylbenzene with the $\mathrm{M}(0.1) / \mathrm{TiO}_{2} \mathrm{photocatalysts}(\mathrm{M}=\mathrm{Pt}$, $\mathrm{Au}$, and $\mathrm{Pd})$. Amount of products (A), alkene conversion, and selectivity to amine (B) with the $\mathrm{M}(0.1) / \mathrm{TiO}{ }_{2}$ photocatalysts $(\mathrm{M}=\mathrm{Pt}, \mathrm{Au}$, and $\mathrm{Pd})$ in the same reaction time, $3 \mathrm{~h}$. To compare the photocatalytic selectivity at the same alkene conversion, the reaction time was controlled as followed, $95 \mathrm{~min}$ for $\mathrm{Pt}(0.1) / \mathrm{TiO}_{2}$, $180 \mathrm{~min}$ for $\mathrm{Au}(0.1) / \mathrm{TiO}_{2}$, and $110 \mathrm{~min}$ for $\mathrm{Pd}(0.1) / \mathrm{TiO}_{2}$, respectively $(\mathbf{C}, \mathbf{D})$.

As mentioned, the photochemical reaction showed an opposite regioselectivity. This result suggests that the reaction proceeds via another reaction mechanism, possibly an alkene molecule itself is directly photoexcited to form an excited complex with ammonia, followed by the formation of amine products, where thermodynamic stability of the products would determine the regioselectivity. At present, although very clear evidences have not been obtained, 3-buten-1-ylbenzene shows photoabsorption in the shorter wavelength region less than $300 \mathrm{~nm}$, aqueous ammonia has no absorption, and the mixture of 3-buten-1-ylbenzene and aqueous ammonia in acetonitrile showed an additional band around 300-400 nm (Figure S2). These facts suggest that an excited complex consisting of alkene and ammonia would be the reaction intermediate in the photochemical hydroamination to produce the Markovnikov product, which is more stable thermodynamically (Scheme S1). Although the photochemical reaction would also competitively take place in the photocatalytic reaction conditions, higher efficiency of the present photocatalysis than the photochemical reaction would give the high regioselectivity to anti-Markovnikov reaction.
Photocatalysts and reaction conditions. Among the examined metal cocatalysts on the $\mathrm{TiO}_{2}$ (anatase) photocatalyst, platinum gave the largest amount of amine and gold showed the highest selectivity of amine when they were compared in the same reaction conditions, where the reaction time was $3 \mathrm{~h}$ (Figure $1 \mathrm{~A}$ and $1 \mathrm{~B}$ ). When compared the selectivity at the same alkene conversion by controlling the reaction time, the Au-loaded photocatalyst provided the largest amount of amine with the highest selectivity (Figure 1C and 1D). This means that the Pt- and Pd-loaded photocatalysts exhibited high reaction rate even for by-product formation, while the Au-loaded photocatalyst selectively promoted the hydroamination though the reaction rate was relatively low.

The largest amount of amine and the highest selectivity to amine were obtained by the photocatalyst with $0.1 \mathrm{wt} \%$ loading amount of the $\mathrm{Au}$ and Pt cocatalysts (Figure S2), which is consistent with the previous study on ammonia decomposition and amination of benzene. ${ }^{23,24}$ 
Table 2. The photocatalytic hydroamination of several alkenes using aqueous ammonia with the $\mathrm{Au}(0.1) / \mathrm{TiO}_{2}$ and $\operatorname{Pt}(0.1) / \mathrm{TiO}_{2}$ photocatalysts ${ }^{\mathrm{a}}$
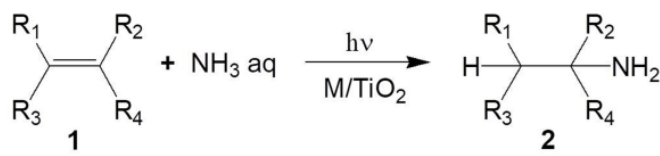

Anti-Markovnikov product

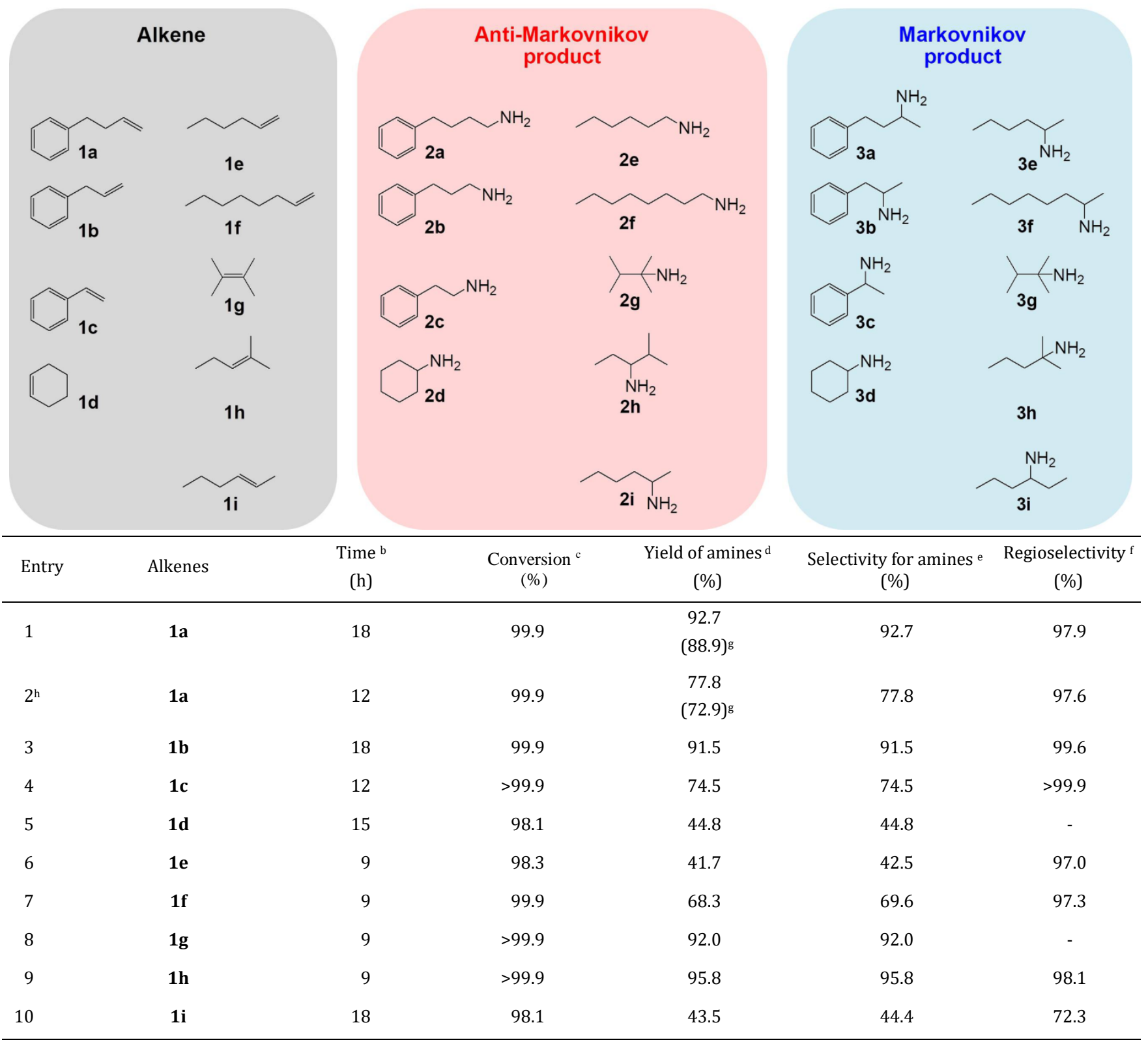

a Catalyst: $150 \mathrm{mg}$ of the $\mathrm{Au}(0.1) / \mathrm{TiO}_{2}$ sample, in which anatase $\mathrm{TiO}_{2}$ was used $\left(300 \mathrm{~m}^{2} \mathrm{~g}^{-1}\right.$, ST-01, Ishihara Sangyo Kaisha); reactants: alkene (1a-1i, 0.4 $\mathrm{mL}$ ), aqueous ammonia $(28 \%, 1.6 \mathrm{~mL})$; solvent: acetonitrile $(4.0 \mathrm{~mL})$; wavelength: $\lambda \geq 300 \mathrm{~nm}$; light intensity: $40 \mathrm{~mW} \mathrm{~cm}^{-2} \mathrm{measured} \mathrm{at} 360 \pm 40 \mathrm{~nm}$

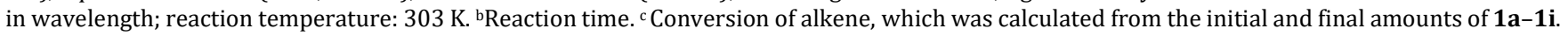
d Yield of amines (2a-2i and 3a-3i), which was calculated from the initial amount of 1a-1i and the obtained amount of 2a-2i and 3a-3i. e Selectivity for amines, which was calculated from the amounts of consumed 1a-1i and obtained $2 \mathbf{a}-\mathbf{2} \mathbf{i}$ and $\mathbf{3 a}-\mathbf{3} \mathbf{i}$. ${ }^{\mathrm{f}}$ Regioselectivity of the anti-Markovnikov amine, which was calculated from the amounts of obtained $\mathbf{2 a - 2 i}$ and $\mathbf{3 a}-\mathbf{3 i}$, where the amount of 1-phenylethanamine (3c) was tentatively estimated by using the GC-FID calibration curve for 2-phenylethanamine (2c) and 2-hexanamine (3e and 2i), 2,3-dimethyl-2-butanamine (2g and 3g), 2-methyl-3-pentanamine (2h), 2-methyl-2-pentanamine (3h), and 3-hexanamine (3i) were tentatively estimated by using the GC-FID calibration curve for 1-hexanamine (2e), respectively. ${ }^{\mathrm{g}}$ Isolated yield. ${ }^{\mathrm{h}}$ Catalyst: $150 \mathrm{mg}$ of the $\mathrm{Pt}(0.1) / \mathrm{TiO}_{2}$ sample. Original data are shown in Table $\mathrm{S} 1$. 
Among three kinds of $\mathrm{TiO}_{2}$ samples examined, the anatase $\mathrm{TiO}_{2}$ sample having a high specific surface area $\left(300 \mathrm{~m}^{2} \mathrm{~g}^{-1}\right)$ gave the most active $\mathrm{Au}(0.1) / \mathrm{TiO}_{2}$ photocatalyst (Figure S3) The higher specific surface area can provide a larger reaction field, and anatase gives a longer lifetime of the electron-hole pairs than rutile, ${ }^{22}$ both of which would contribute to the best photocatalytic performance.

With increasing the reaction temperature from $273 \mathrm{~K}$ to 303 $\mathrm{K}$ in the presence of the $\mathrm{Au}(0.1) / \mathrm{TiO}_{2}$ or $\mathrm{Pt}(0.1) / \mathrm{TiO}_{2}$ photocatalysts, the amount of obtained amine increased and reached to the maximum at $303 \mathrm{~K}$ (Figure S4). But, it decreased at $313 \mathrm{~K}$ because of the vaporization of aqueous ammonia above at $310 \mathrm{~K}$. At lower temperature than $273 \mathrm{~K}$, aqueous ammonia and alkenes became immiscible even in the presence of the acetonitrile solvent. The pseudo-Arrhenius plots for the products formation obtained from the data at 273-303 K (Figure S5) gave the apparent activation energies as 6.9 and $3.3 \mathrm{~kJ} \mathrm{~mol}^{-1}$ for the produced amines and others, respectively, with the $\mathrm{Au}(0.1) / \mathrm{TiO}_{2}$ photocatalyst, and 6.1 and $2.1 \mathrm{~kJ} \mathrm{~mol}^{-1}$ with the $\mathrm{Pt}(0.1) / \mathrm{TiO}_{2}$ photocatalyst, respectively. These values are very low, which are typical values for photocatalysis, ${ }^{26,27}$ meaning that this photocatalytic hydroamination was mainly promoted by not thermal energy but photoenergy. In other words, the thermal energy does not affect the reaction rate so much in this reaction, suggesting that these loaded metals would contribute to the amine formation as not metal catalysts but cocatalysts for the $\mathrm{TiO}_{2}$ photocatalyst as mentioned above.

Scope of the photocatalytic hydroamination. The reaction tests for several alkenes were carried out with various reaction time (Table 2). The 3-buten-1-ylbenzene (1a) gave high yield of amines of $>92 \%$ with high selectivity as mentioned above (Table 2, entry 1 ). With the $\mathrm{Au}(0.1) / \mathrm{TiO}_{2}$ photocatalyst, the yield of amine (2a with a tiny amount of $\mathbf{3 a}$ ) evaluated by GC was $92.7 \%$. The yielded amount of them was $346.3 \mathrm{mg}$ from $359.2 \mathrm{mg}$ of 3-buten-1-ylbenzene (1a) and the isolated yield was $88.9 \%$. Analyses by ${ }^{1} \mathrm{H}-\mathrm{NMR}$ and ${ }^{13} \mathrm{C}$-NMR confirmed the high yields (Figure S6). In this case, possible successive reaction products such as the secondary or tertiary amines and imines were scarcely produced even when the reaction time was prolonged. Moreover, when the reaction was carried out with amines instead of alkenes as a reactant in the presence of ammonia (Table S2), amines did not react with ammonia or amines, while ammonia was decomposed to hydrogen and nitrogen. ${ }^{23}$ This means that photocatalyst can predominantly activate not amines but ammonia and the amide radical does not react with amines. This is the reason why the successive reaction hardly took place in the present reaction system. This is a unique property of the present photocatalytic system.

The $\mathrm{Pt}(0.1) / \mathrm{TiO}_{2}$ photocatalyst converted 3-buten-1-ylbenzene (1a) to not only the amines but also byproducts via undesirable side reactions such as bimolecular reaction products from alkenes (major) and reaction with acetonitrile (minor), although the regioselectivity among amines was high (Table 2, entry 2). When with the $\mathrm{Pt}(0.1) / \mathrm{TiO}_{2}$ photocatalyst, the GC yield of amine (2a with a tiny amount of 3a) was $77.8 \%$. The yielded amount of them was 284.0 $\mathrm{mg}$ from $359.2 \mathrm{mg}$ of 3-buten-1-ylbenzene (1a) and the isolated yield was $72.9 \%$. Analyses by ${ }^{1} \mathrm{H}-\mathrm{NMR}$ and ${ }^{13} \mathrm{C}$-NMR confirmed the high yields (Figure S7). The $\mathrm{Pt}(0.1) / \mathrm{TiO}_{2}$ photocatalyst also performed the photocatalytic hydroamination from the same amount of alkenes as that case of the $\mathrm{Au}(0.1) / \mathrm{TiO}_{2}$ photocatalyst, but undesirable side reactions increased. Ultimately, the $\mathrm{Au}(0.1) / \mathrm{TiO}_{2}$ photocatalyst showed largest amount of amines than $\mathrm{Pt}(0.1) / \mathrm{TiO}_{2}$ photocatalyst.

Allylbenzene (1b) also gave amines similarly with a high selectivity (Table 2, entry 3). Slightly lower yield of amine was obtained from styrene (1c) because of photopolymerization (Table 2, entry 4). ${ }^{28,29}$ The amine selectivity was low in other alkenes, such as cyclohexene, 1-hexene, and 1-octene (1d, 1e, and 1f) due to undesirable above-mentioned side reactions (Table 2, entries 5-7). The alkenes with a phenyl group gave the high selectivity to amines than the linear alkene without phenyl group, implying that the phenyl group might stabilize the radical intermediates.

The internal alkenes without a phenyl group, 2,3-dimethyl2-butene (1g) and 2-methyl-2-pentene (1h), were also converted to amines with high yield such as $92 \%$ and $>95 \%$, respectively, and the selectivity to amines was also high (Table 2, entries 8 and 9). On the other hand, other alkenes without a phenyl group such as the cyclohexene (1d), 1-hexene (1e), 1-octene (1f), and (2E)-2-hexene (1i) resulted in low selectivity to amines due to the side reactions with another alkene molecule or solvent (Table 2, entries 5-7 and 10). This means that mono- and disubstituted alkene without a phenyl group showed low selectivity to amines while tri- and tetrasubstituted alkene showed high selectivity to amines.

As listed in Table 2, the values of the regioselectivity to antiMarkovnikov product for $\mathbf{1 a - 1 h}$ were very high such as 97.0-99.9\%, except for the case of 2-hexene (1i). Generally, regioselectivity is determined by the thermodynamic stability of the products or reaction intermediates, and Markovnikov primary amines are usually thermodynamically more stable than anti-Markovnikov primary amines (Table S3), which cannot explain the high regioselectivity to anti-Markovnikov product. Therefore, the very high regioselectivity to anti-Markovnikov product should originate from the thermodynamic stability of the radical intermediate to give anti-Markovnikov product (Scheme 3). This is consistent with the conclusion of the previous study for anti-Markovnikov alkene hydration. ${ }^{25}$ The low regioselectivity (72\%) in the case of 2-hexene (1i) can be explained by the similar stability of the anti-Markovnikov and Markovnikov intermediates. In the case of photochemical hydroamination, the regioselectivity seems to be determined by the stability of the Markovnikov products since the complex of the reactants would be directly excited by photoenergy.

\section{CONCLUSIONS}

We successfully found a new route for the synthesis of primary amines using aqueous ammonia by anti-Markovnikov hydroamination with metal-loaded $\mathrm{TiO}_{2}$ photocatalysts in acetonitrile solvent around room temperature. The primary amines were selectively obtained from several amines with an $\mathrm{Au}$-loaded $\mathrm{TiO}_{2}$ photocatalyst. According to the unique reaction mechanism, the photocatalytic hydroamination 
proceeded with a high regioselectivity for the anti-Markovnikov product such as more than $97 \%$. The regioselectivity was quite different from usual catalytic and photochemical hydroamination. The high anti-Markovnikov regioselectivity would be determined by the thermodynamic stability of the radical intermediate formed from alkene and amide radical. It is also a unique property of this reaction system that the successive reactions hardly take place to produce secondary and tertiary amines and imines, which realizes the high and selective yield of anti-Markovnikov hydroamination products.

\section{EXPERIMENTAL SECTION}

Materials. Three titanium oxide samples, JRC-TIO-6 (rutile, $100 \mathrm{~m}^{2} \mathrm{~g}^{-1}$, Catalysis Society of Japan), SSP-M (anatase, 100 $\mathrm{m}^{2} \mathrm{~g}^{-1}$, Sakai Chemical Industry), and ST-01 (anatase, 300 $\mathrm{m}^{2} \mathrm{~g}^{-1}$, Ishihara Sangyo Kaisha), were employed. Precursors of the metal cocatalyst were chloroplatinic acid hexahydrate $\left(\mathrm{H}_{2} \mathrm{PtCl}_{6} \cdot 6 \mathrm{H}_{2} \mathrm{O}\right.$, Nacalai Tesque, $\left.\geq 98.5 \%\right)$, gold chloride acid tetrahydrate $\left(\mathrm{HAuCl}_{4} \cdot 4 \mathrm{H}_{2} \mathrm{O}\right.$, Nacalai Tesque, $\left.\geq 99.0 \%\right)$, and palladium chloride $\left(\mathrm{PdCl}_{2}\right.$, Nacalai Tesque, $\left.\geq 99.0 \%\right)$. Other reagents were 3-buten-1-ylbenzene (Sigma-Aldrich, $99.0 \%$ ), aqueous ammonia solution (Nacalai Tesque, 28.0\%), acetonitrile (Nacalai Tesque, 99.8\%), 4-phenyl-2butanamine (Tokyo Chemical Industry, >98.0\%), 4-phenyl1-butanamine (Tokyo Chemical Industry, >98.0\%), 1,1'[(1E,3E)-1,3-Butadiene-1,4-diyl]dibenzene (Tokyo Chemical Industry, $>99.0 \%$ ), styrene (Tokyo Chemical Industry, $>99.0 \%$ ), 2-phenylethanamine (Tokyo Chemical Industry, $>98.0 \%$ ), 1-phenylethanamine (Tokyo Chemical Industry, $>98.0 \%$ ), allylbenzene (Tokyo Chemical Industry, >98.0\%), 3-phenyl-1-propanamine (Sigma-Aldrich, 98.0\%), cyclohexene (Nacalai Tesque, $\geq 98.0 \%$ ), cyclohexanamine (Nacalai Tesque, $\geq 98.0 \%$ ), 1-hexene (Nacalai Tesque, $\geq 98.0 \%$ ), 1-hexanamine (Tokyo Chemical Industry, $>99.0 \%$ ), 1-octene (Tokyo Chemical Industry, >99.0\%), 1octanamine (Nacalai Tesque, $\geq 98.0 \%$ ), 2-octanamine (Tokyo Chemical Industry, $>98.0 \%$ ), 2,3-dimethyl-2-butene (Tokyo Chemical Industry, >96.0\%), 2-methyl-2-pentene (Tokyo Chemical Industry, >95.0\%), (2E)-2-hexene (Tokyo Chemical Industry, >99.0\%), 1-decane (Nacalai Tesque, 98.0\%), methanol (Nacalai Tesque, 99.8\%), ethanol (Nacalai Tesque, 99.5\%), deuterated chloroform (Nacalai Tesque, $\geq 98.0 \%$ ), and $\mathrm{N}, \mathrm{N}$-Diethylethanamine (Nacalai Tesque, $\geq 98.0 \%$ ). These reagents were used without further refining.

Preparation of photocatalysts. Metal-loaded titanium oxide $\left(\mathrm{M} / \mathrm{TiO}_{2}, \mathrm{M}=\mathrm{Pt}, \mathrm{Au}\right.$, and $\left.\mathrm{Pd}\right)$ was prepared by a photodeposition method. The $4.0 \mathrm{~g}$ of titanium oxide powder with ion exchanged water $(300 \mathrm{~mL})$ in a $500 \mathrm{~mL}$ beaker was vigorously stirred, followed by pre-irradiation of UV and visible light from a xenon lamp (300 W, PE300BUV) at room temperature for $30 \mathrm{~min}$. After addition of methanol (100 $\mathrm{mL}$ ) and an aqueous solution of metal precursor, the mixture was stirred for $15 \mathrm{~min}$, photoirradiated from the xenon lamp for $1 \mathrm{~h}$. The suspension was filtered, washed with ion exchanged water, and dried at $323 \mathrm{~K}$ overnight. In the present paper, $x$ wt.\% of metal-loaded titanium oxide sample was referred to as $\mathrm{M}(x) / \mathrm{TiO}_{2}(x=0.01-1.0)$.
Photocatalytic reaction test. Photocatalytic reaction test for hydroamination was carried out by using a Pyrex test tube (70 mL, $21 \mathrm{~mm}$ in diameter). $150 \mathrm{mg}$ of the prepared $\mathrm{M}(x) / \mathrm{TiO}_{2}$ was placed in the Pyrex test tube and pre-irradiated with the $300 \mathrm{~W}$ xenon lamp in an air atmosphere for 30 min to clean the photocatalyst surface. Then, after adding $4.0 \mathrm{~mL}$ of acetonitrile and $1.6 \mathrm{~mL}$ of aqueous ammonia, the test tube was capped with a septum and the gas phase was replaced by argon gas with stirring for $30 \mathrm{~min}$. The test tube was introduced in a beaker which was filled by water with ice to maintain the reaction temperature at $303 \mathrm{~K}$ and $0.4 \mathrm{~mL}$ of 3-buten-1-ylbenzene was added by a syringe. The reaction mixture was irradiated with the xenon lamp (300 $\mathrm{W})$ with stirring for $3 \mathrm{~h}$ at $303 \mathrm{~K}$. After the irradiation, the products in the gas phase were analyzed by a GC-TCD (Shimadzu, GC-8A). Afterward, $n$-decane as an internal standard in $15 \mathrm{~mL}$ of ethanol was added into the resulting reaction mixture, stirred for $5 \mathrm{~min}$, and filtered by a PTFE $(0.45 \mu \mathrm{m})$ syringe filter. Products in the liquid phase were analyzed by a GC-FID, Shimadzu, GC-2014) and a GC-MS (Shimadzu, GCMS-QP2020). The selectivity and regioselectivity of amine were calculated from the GC-FID area. Also, the produced amine was isolated by silica gel column chromatography. The isolated yield of amine was analyzed by NMR (JEOL ECS-400, $500 \mathrm{MHz}$ ).

\section{ASSOCIATED CONTENT}

\section{Supporting Information.}

Additional data and NMR analysis. This material is available free of charge via the Internet at http://pubs.acs.org.

\section{AUTHOR INFORMATION}

\section{Corresponding Author}

Hisao Yoshida - ${ }^{\dagger}$ Department of Interdisciplinary Environment, Graduate School of Human and Environmental Studies, Kyoto University, Kyoto, Japan. ${ }^{\ddagger}$ Elements Strategy Initiative for Catalysts and Batteries (ESICB), Kyoto University, Kyoto, Japan. orcid.org/ 0000-0002-2540-0225;

E-mail: yoshida.hisao.2a@kyoto-u.ac.jp

\section{Authors}

Soyeong Park - Department of Interdisciplinary Environment, Graduate School of Human and Environmental Studies, Kyoto University, Kyoto, Japan. orcid.org/0000-0002-8056-3959 Jaeyoung Jeong - Department of Interdisciplinary Environment, Graduate School of Human and Environmental Studies, Kyoto University, Kyoto, Japan.

Ken-ichi Fujita - Department of Interdisciplinary Environment, Graduate School of Human and Environmental Studies, Kyoto University, Kyoto, Japan.

Akira Yamamoto - Department of Interdisciplinary Environment, Graduate School of Human and Environmental Studies, Kyoto University, Kyoto, Japan. Elements Strategy Initiative for Catalysts and Batteries (ESICB), Kyoto University, Kyoto, Japan.

\section{Notes}

The authors declare no competing financial interest.

\section{ACKNOWLEDGMENT}


The authors acknowledge Dr. Hayato Yuzawa and Mr. Yuichiro Wada, who were previously in Nagoya University, for their preliminary experiments. This work was financially supported by the joint research program of the Artificial Photosynthesis, Osaka City University, the Program for Element Strategy Initiative for Catalysts \& Batteries (ESICB, JPMXP0112101003) commissioned by the MEXT of Japan, and a Grant-in-Aid for Young Scientists (19K15359) from the Japan Society for the Promotion of Science (JSPS).

\section{REFERENCES}

(1) Roose, P.; Eller, K.; Henkes, E.; Rossbacher, R.; Höke, H. Amines, Aliphatic. In Ullmann's Encyclopedia of Industrial Chemistry; 2015; pp 1-50.

(2) Müller, T. E.; Beller, M. Metal-Initiated Amination of Alkenes and Alkynes. Chem. Rev. 1998, 98 (2), 675-703.

(3) Adams, J. P.; Robertson, G. Imines, Enamines and Related Functional Groups. Contemp. Org. Synth. 1997, 4 (3), 183-195.

(4) Kawatsura, M.; Hartwig, J. F. Palladium-Catalyzed Intermolecular Hydroamination of Vinylarenes Using Arylamines. J. Am. Chem. Soc. 2000, 122 (39), 9546-9547.

Li, K.; Horton, P. N.; Hursthouse, M. B.; Hii, K. K. (Mimi). Airand Moisture-Stable Cationic (Diphosphine)Palladium(II) Complexes as Hydroamination Catalysts X-Ray Crystal Structures of Two [(Diphosphine)Pd(NCMe) $\left.\left(\mathrm{OH}_{2}\right)\right]^{2+}[\mathrm{OTf}]_{2}^{-}$ Complexes. J. Organomet. Chem. 2003, 665 (1-2), 250-257.

(6) Beller, M.; Seayad, J.; Tillack, A.; Jiao, H. Catalytic Markovnikov and Anti-Markovnikov Functionalization of Alkenes and Alkynes: Recent Developments and Trends. Angew. Chemie - Int. Ed. 2004, 43 (26), 3368-3398.

(7) Hesp, K. D.; Stradiotto, M. Rhodium- and Iridium-Catalyzed Hydroamination of Alkenes. ChemCatChem 2010, 2 (10), 11921207.

Zhou, X.-L.; Fan Yang, H.-L. S.; Yin, Y.-N.; Ye, W.-T.; Zhu, R Cobalt-Catalyzed Intermolecular Hydrofunctionalization of Alkenes: Evidence for a Bimetallic Pathway. J. Am. Chem. Soc. 2019, 141 (18), 7250-7255.

Shen, X.; Chen, X.; Chen, J.; Sun, Y.; Cheng, Z.; Lu, Z. LigandPromoted Cobalt-Catalyzed Radical Hydroamination of Alkenes. Nat. Commun. 2020, 11 (1), 783.

(10) Beller, M.; Trauthwein, H.; Eichberger, M.; Breindl, C.; Herwig J. The First Rhodium-Catalyzed Anti-Markovnikov Hydroamination : Studies on Hydroamination and Oxidative Amination of Aromatic Olefins. Chem. A Eur. J. 1999, 5 (4), 1306-1319.

(11) Tillack, A.; Castro, I. G.; Hartung, C. G.; Beller, M. AntiMarkovnikov Hydroamination of Terminal Alkynes. Angew. Chemie - Int. Ed. 2002, 41 (14), 2541-2543.

(12) Utsunomiya, M.; Kuwano, R.; Kawatsura, M.; Hartwig, J. F. Rhodium-Catalyzed Anti-Markovnikov Hydroamination of Vinylarenes. J. Am. Chem. Soc. 2003, 125, 5608-5609.

(13) Utsunomiya, M.; Hartwig, J. F. Ruthenium-Catalyzed AntiMarkovnikov Hydroamination of Vinylarenes. J. Am. Chem. Soc. 2004, 126 (9), 2702-2703.

(14) Bronner, S. M.; Grubbs, R. H. Formal Anti-Markovnikov Hydroamination of Terminal Olefins. Chem. Sci. 2014, 5 (1), 101-106.
(15) Michon, C.; Abadie, M. A.; Medina, F.; Agbossou-Niedercorn, F. Recent Metal-Catalysed Asymmetric Hydroaminations of Alkenes. J. Organomet. Chem. 2017, 847, 13-27.

(16) Musacchio, A. J.; Lainhart, B. C.; Zhang, X.; Naguib, S. G.; Sherwood, T. C.; Knowles, R. R. Catalytic Intermolecular Hydroaminations of Unactivated Olefins with Secondary Alkyl Amines. Science 2017, 355 (6326), 727-730.

(17) Lardy, S. W.; Schmidt, V. A. Intermolecular Radical Mediated Anti-Markovnikov Alkene Hydroamination Using NHydroxyphthalimide. J. Am. Chem. Soc. 2018, 140 (39), 1231812322.

(18) Sheng, G.; Yang, J. C.; Buchwald, S. L. A Practical Electrophilic Nitrogen Source for the Synthesis of Chiral Primary Amines by Copper-Catalyzed Hydroamina. $J$. Am Chem. Soc. 2018, 140 (46), 15976-15984.

(19) Qilei, Z.; Graff, D. E.; Knowles, R. R. Intermolecular AntiMarkovnikov Hydroamination of Unactivated Alkenes with Sulfonamides Enabled by Proton-Coupled Electron Transfer. $J$. Am. Chem. Soc. 2018, 140 (2), 741-747.

(20) Miller, D. C.; Ganley, J. M.; Musacchio, A. J.; Sherwood, T. C.; Ewing, W. R.; Knowles, R. R. Anti-Markovnikov Hydroamination of Unactivated Alkenes with Primary Alkyl Amines. J. Am. Chem. Soc. 2019, 141 (42), 16590-16594.

Fujishima, A.; Zhang, X.; Tryk, D. A. $\mathrm{TiO}_{2}$ Photocatalysis and Related Surface Phenomena. Surf. Sci. Rep. 2008, 63 (12), 515582.

Jovic, V.; Al-Azri, Z. H. N.; Chen, W. T.; Sun-Waterhouse, D.; Idriss, H.; Waterhouse, G. I. N. Photocatalytic $\mathrm{H}_{2}$ Production from Ethanol-Water Mixtures over $\mathrm{Pt} / \mathrm{TiO}_{2}$ and $\mathrm{Au} / \mathrm{TiO}_{2}$ Photocatalysts: A Comparative Study. Top. Catal. 2013, 56 (12), 1139-1151.

Yuzawa, H.; Mori, T.; Itoh, H.; Yoshida, H. Reaction Mechanism of Ammonia Decomposition to Nitrogen and Hydrogen over Metal Loaded Titanium Oxide Photocatalyst. $J$. Phys. Chem. C 2012, 116 (6), 4126-4136.

Yuzawa, H.; Kumagai, J.; Yoshida, H. Reaction Mechanism of Aromatic Ring Amination of Benzene and Substituted Benzenes by Aqueous Ammonia over Platinum-Loaded Titanium Oxide Photocatalyst. J. Phys. Chem. C 2013, 117 (21), 11047-11058.

(25) Yuzawa, H.; Yoneyama, S.; Yamamoto, A.; Aoki, M.; Otake, K.; Itoh, H.; Yoshida, H. Anti-Markovnikov Hydration of Alkenes over Platinum-Loaded Titanium Oxide Photocatalyst. Catal. Sci. Technol. 2013, 3 (7), 1739-1749.

Tyagi, A.; Matsumoto, T.; Yamamoto, A.; Kato, T.; Yoshida, H. Metal Cocatalyst Directing Photocatalytic Acetonylation of Toluene via Dehydrogenative Cross-Coupling with Acetone. Catal. Lett. 2020, 150 (1), 31-38.

Shimura, K.; Maeda, K.; Yoshida, H. Thermal Acceleration of Electron Migration in Gallium Oxide Photocatalysts. J. Phys. Chem. C 2011, 115 (18), 9041-9047.

Chen, H. B.; Chang, T. C.; Chiu, Y. S.; Ho, S. Y. Photopolymerization of Styrene and Methyl Methacrylate with Poiy(Methylphenylsilane) as Photoinitiator. J. Polym. Sci. Part A Polym. Chem. 1996, 34 (6), 679-685.

Kodaira, T.; Hayashi, K.; Ohnishi, T. Photopolymerization of Styrene in the Presence of Oxygen. Role of the Charge-Transfer Complex. Polym. J. 1973, pp 1-9. 


\section{Supporting Information}

\section{Anti-Markovnikov Hydroamination of Alkenes with Aqueous Ammonia by Metal-Loaded Titanium Oxide Photocatalyst}

Soyeong Park ${ }^{\dagger}$, Jaeyoung Jeong ${ }^{\dagger}$, Ken-ichi Fujita ${ }^{\dagger}$, Akira Yamamoto ${ }^{\dagger, \dagger}$ \& Hisao Yoshida ${ }^{\dagger, \dagger *}$

'Department of Interdisciplinary Environment, Graduate School of Human and Environmental Studies, Kyoto University, Kyot o, Japan

${ }^{\sharp}$ Elements Strategy Initiative for Catalysts and Batteries (ESICB), Kyoto University, Kyoto, Japan

*Corresponding Author; E-mail: yoshida.hisao.2a@kyoto-u.ac.jp

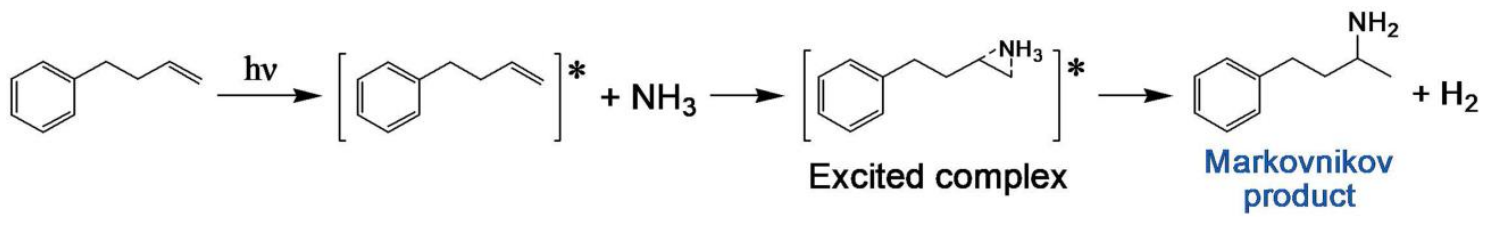

Scheme S1. Proposed mechanism of photochemical hydroamination without a photocatalyst. 
Table S1. The detailed data for Table 2

\begin{tabular}{ll}
\hline entry alkenes & details \\
\hline
\end{tabular}<smiles>NC=CCCc1ccccc1</smiles><smiles>NCCCCc1ccccc1</smiles><smiles>CC(N)C[Pb]</smiles>

Catalyst: $150 \mathrm{mg}$, reactants: alkene (3-buten-1-ylbenzene (1a), $0.4 \mathrm{~mL}, 2.61 \mathrm{mmol})$, aqueous ammonia $(28 \%, 1.6 \mathrm{~mL}, 23.7 \mathrm{mmol})$, solvent: acetonitrile $(4.0 \mathrm{~mL}, 73.1 \mathrm{mmol})$, wavelength: $\lambda \geq 300 \mathrm{~nm}$, light intensity: $40 \mathrm{~mW} \mathrm{~cm}{ }^{-2}$ measured at $360 \pm 40 \mathrm{~nm}$ in wavelength. The yellow oil, 4-phenyl-1-butanamine (2a) and 4-phenyl-2-butanamine (3a), were obtained with $90.6 \%$ and $2.05 \%$ yields, respectively. The major byproducts were bimolecular reaction products from alkene with molecular weight of 262 and 264 detected by GC-MS, but quantitative analysis was not performed.
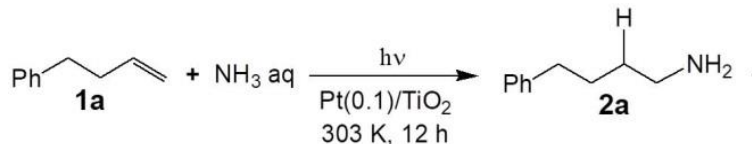<smiles>CC(N)CCc1ccccc1</smiles>

Catalyst: $150 \mathrm{mg}$, reactants: alkene (3-buten-1-ylbenzene (1a), $0.4 \mathrm{~mL}, 2.61 \mathrm{mmol}$ ), aqueous ammonia $(28 \%, 1.6 \mathrm{~mL}, 23.7 \mathrm{mmol})$, solvent: acetonitrile $(4.0 \mathrm{~mL}, 73.1 \mathrm{mmol})$, wavelength: $\lambda \geq 300 \mathrm{~nm}$, light intensity: $40 \mathrm{~mW} \mathrm{~cm}{ }^{-2}$ measured at $360 \pm 40 \mathrm{~nm}$ in wavelength. The yellow oil, 4-phenyl-1-butanamine (2a) and 4-phenyl-2-butanamine (3a), were obtained with $75.9 \%$ and $1.86 \%$ yields, respectively. The major byproducts were bimolecular reaction products from alkene with molecular weight of 262 and 264 detected by GC-MS, but quantitative analysis was not performed.

styrene

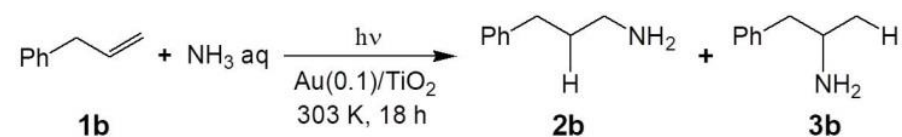

Catalyst: $150 \mathrm{mg}$, reactants: alkene (allylbenzene (1b), $0.4 \mathrm{~mL}, 3.02 \mathrm{mmol}$ ), aqueous ammonia $(28 \%, 1.6 \mathrm{~mL}, 23.7 \mathrm{mmol})$, solvent: acetonitrile $(4.0 \mathrm{~mL}, 73.1 \mathrm{mmol})$, wavelength: $\lambda \geq 300 \mathrm{~nm}$, light intensity: $40 \mathrm{~mW} \mathrm{~cm}{ }^{-2}$ measured at $360 \pm 40 \mathrm{~nm}$ in wavelength. The 3phenyl-1-propanamine (2b) and 3-phenyl-2-propanamine (3b) were obtained with $91.1 \%$ and $0.329 \%$ yields, respectively. The major byproducts were bimolecular reaction product from alkene with molecular weight of 236 detected by GC-MS, but quantitative analysis was not performed.

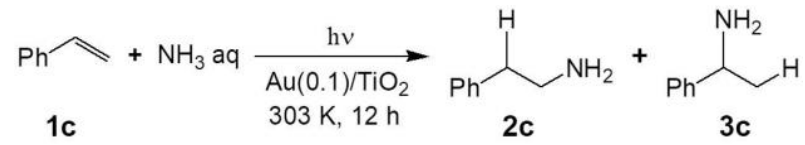

Catalyst: $150 \mathrm{mg}$, reactants: alkene (styrene (1c), $0.4 \mathrm{~mL}, 3.49 \mathrm{mmol}$ ), aqueous ammonia (28\%, $1.6 \mathrm{~mL}, 23.7 \mathrm{mmol})$, solvent: acetonitrile $(4.0 \mathrm{~mL}, 73.1 \mathrm{mmol})$, wavelength: $\lambda \geq 300$ $\mathrm{nm}$, light intensity: $40 \mathrm{~mW} \mathrm{~cm}{ }^{-2}$ measured at $360 \pm 40 \mathrm{~nm}$ in wavelength. The 2phenylethanamine (2c) and 1-phenylethanamine (3c) were obtained with $74.4 \%$ and $0.005 \%$ yields, respectively. The major byproducts were bimolecular reaction product from alkene with molecular weight of 208 detected by GC-MS, but quantitative analysis was not performed.

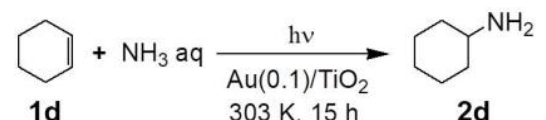

Catalyst: $150 \mathrm{mg}$, reactants: alkene (cyclohexene $(\mathbf{1 d}), 0.4 \mathrm{~mL}, 3.95 \mathrm{mmol}$ ), aqueous ammonia $(28 \%, 1.6 \mathrm{~mL}, 23.7 \mathrm{mmol})$, solvent: acetonitrile $(4.0 \mathrm{~mL}, 73.1 \mathrm{mmol})$, wavelength: $\lambda \geq 300 \mathrm{~nm}$, light intensity: $\lambda \geq 300 \mathrm{~nm}$, Light intensity; $40 \mathrm{~mW} \mathrm{~cm}^{-2}$ measured at $360 \pm 40$ $\mathrm{nm}$ in wavelength. The cyclohexanamine (2d) was obtained with $44.8 \%$ yield. The major byproducts were bimolecular reaction product from alkene with molecular weight of 162 detected by GC-MS, but quantitative analysis was not performed. 


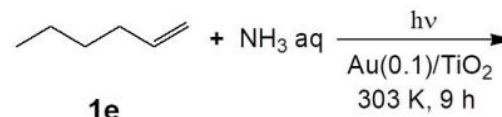<smiles>CCCCC(C)CN</smiles><smiles>CCCCC(C)N</smiles>

Catalyst: $150 \mathrm{mg}$, reactants: alkene (1-hexene (1e), $0.4 \mathrm{~mL}, 3.20 \mathrm{mmol})$, aqueous ammonia (28\%, $1.6 \mathrm{~mL}, 23.7 \mathrm{mmol})$, solvent: acetonitrile $(4.0 \mathrm{~mL}, 73.1 \mathrm{mmol})$, wavelength: $\lambda \geq 300$ $\mathrm{nm}$, light intensity: $40 \mathrm{~mW} \mathrm{~cm}{ }^{-2}$ measured at $360 \pm 40 \mathrm{~nm}$ in wavelength. The 1-hexanamine (2e) and 2-hexanamine (3e) were obtained with $40.5 \%$ and $1.23 \%$ yields, respectively. The major byproducts were bimolecular reaction product from alkene with molecular weight of 168 detected by GC-MS, but quantitative analysis was not performed.

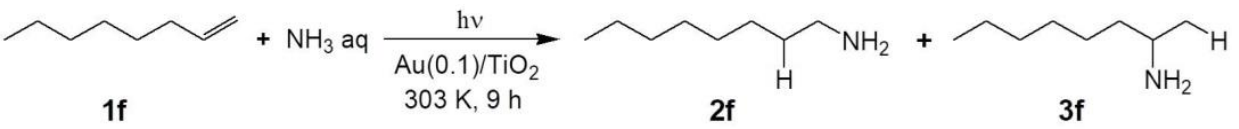

Catalyst: $150 \mathrm{mg}$, reactants: alkene (1-octene (1f), $0.4 \mathrm{~mL}, 2.55 \mathrm{mmol})$, aqueous ammonia $(28 \%, 1.6 \mathrm{~mL}, 23.7 \mathrm{mmol})$, solvent: acetonitrile $(4.0 \mathrm{~mL}, 73.1 \mathrm{mmol})$, wavelength: $\lambda \geq 300$ $\mathrm{nm}$, light intensity: $40 \mathrm{~mW} \mathrm{~cm}{ }^{-2}$ measured at $360 \pm 40 \mathrm{~nm}$ in wavelength. The 1-octanamine (2f) and 2-octanamine (3f) were obtained with $66.4 \%$ and $1.87 \%$ yields, respectively. The major byproducts were bimolecular reaction product from alkene with molecular weight of 224 detected by GC-MS, but quantitative analysis was not performed.

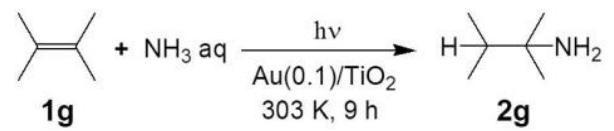

Catalyst: $150 \mathrm{mg}$, reactants: alkene (2,3-dimethyl-2-butene (1g), $0.4 \mathrm{~mL}, 3.37 \mathrm{mmol}$ ), aqueous ammonia $(28 \%, 1.6 \mathrm{~mL}, 23.7 \mathrm{mmol})$, solvent: acetonitrile $(4.0 \mathrm{~mL}, 73.1 \mathrm{mmol})$, wavelength: $\lambda \geq 300 \mathrm{~nm}$, light intensity: $40 \mathrm{~mW} \mathrm{~cm}{ }^{-2}$ measured at $360 \pm 40 \mathrm{~nm}$ in wavelength. The 2,3-dimethyl-2-butanamine (2g) was obtained with $92.0 \%$ yield. The major byproducts were bimolecular reaction product from alkene with molecular weight of 166 detected by GC-MS, but quantitative analysis was not performed.

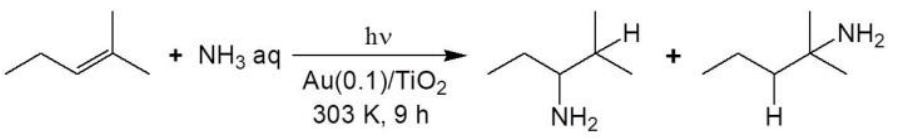

$1 \mathrm{~h}$

$2 \mathrm{~h}$

3h

Catalyst: $150 \mathrm{mg}$, reactants: alkene (2-methyl-2-pentene (1h), $0.4 \mathrm{~mL}, 3.28 \mathrm{mmol})$, aqueous ammonia $(28 \%, 1.6 \mathrm{~mL}, 23.7 \mathrm{mmol})$, solvent: acetonitrile $(4.0 \mathrm{~mL}, 73.1 \mathrm{mmol})$, wavelength: $\lambda \geq 300 \mathrm{~nm}$, light intensity: $40 \mathrm{~mW} \mathrm{~cm}{ }^{-2}$ measured at $360 \pm 40 \mathrm{~nm}$ in wavelength. The 2methyl-3-pentanamine (2h) and 2-methyl-2-pentanamine (3h) were obtained with $94.0 \%$ and $1.85 \%$ yields, respectively. The major byproducts were bimolecular reaction product from alkene with molecular weight of 166 detected by GC-MS, but quantitative analysis was not performed.

\section{0 (2E)-2-hexene}

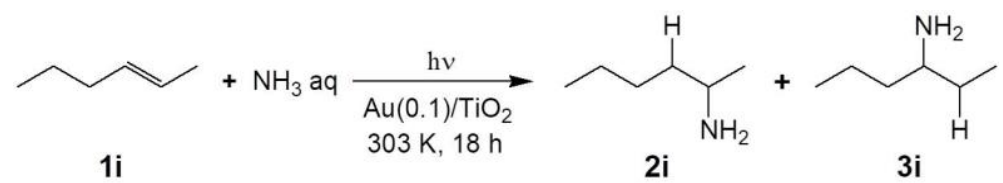

Catalyst: $150 \mathrm{mg}$, reactants: alkene ((2E)-2-hexene (1i), $0.4 \mathrm{~mL}, 3.23 \mathrm{mmol})$, aqueous ammonia $(28 \%, 1.6 \mathrm{~mL}, 23.7 \mathrm{mmol})$, solvent: acetonitrile $(4.0 \mathrm{~mL}, 73.1 \mathrm{mmol})$, wavelength: $\lambda \geq 300 \mathrm{~nm}$, light intensity: $40 \mathrm{~mW} \mathrm{~cm}{ }^{-2}$ measured at $360 \pm 40 \mathrm{~nm}$ in wavelength. The 2hexanamine (2i) and 3-hexanamine (3i) were obtained with $31.5 \%$ and $12.1 \%$ yields, respectively. The major byproducts were bimolecular reaction products from alkene with molecular weight of 166 and 168 detected by GC-MS, but quantitative analysis was not performed. 
Table S2. The reaction of amines as the reactants in the presence of ammonia with the photocatalyst ${ }^{a}$

\begin{tabular}{|c|c|c|c|c|c|c|c|c|c|}
\hline \multirow[b]{2}{*}{ entry } & \multirow[b]{2}{*}{ amines } & \multirow{2}{*}{$\begin{array}{c}\text { initial amount } \\
\text { of amines } \\
\text { /mmol }\end{array}$} & \multicolumn{6}{|c|}{ obtained products/ $\mu$ mol } & \multirow{2}{*}{$\begin{array}{c}\text { conversion } \\
(\%)\end{array}$} \\
\hline & & & $\mathrm{N}_{2}$ & $\mathrm{H}_{2}$ & $2 a$ & $\mathbf{3 a}$ & imines & $\begin{array}{c}\text { other } \\
\text { amines } \\
\text { am }\end{array}$ & \\
\hline 1 & $\begin{array}{l}\text { 4-phenyl-1-butanamine } \\
\qquad(\mathbf{2 a})\end{array}$ & 2.48 & 1.34 & 4.17 & 2475 & - & - & - & 0.20 \\
\hline 2 & $\begin{array}{l}\text { 4-phenyl-2-butanamine } \\
\text { (3a) }\end{array}$ & 2.42 & 1.31 & 4.06 & 8.32 & 2408 & - & - & 0.57 \\
\hline
\end{tabular}

${ }^{\mathrm{a}}$ Catalyst: $\mathrm{Au}(0.1) / \mathrm{TiO}_{2} 150 \mathrm{mg}$, aqueous ammonia $(28 \%, 1.6 \mathrm{~mL}, 23.7 \mathrm{mmol})$, solvent: acetonitrile $(4.0 \mathrm{~mL}, 73.1 \mathrm{mmol})$, wavelength of the irradiated light: $\lambda \geq 300 \mathrm{~nm}$, light intensity: $40 \mathrm{~mW} \mathrm{~cm}{ }^{-2}$ measured at $360 \pm 40 \mathrm{~nm}$ in wavelength, reaction time: $3 \mathrm{~h}$, reaction temperature: $303 \mathrm{~K}, \mathrm{TiO}_{2}$ used; anatase, $300 \mathrm{~m}^{2} \mathrm{~g}^{-1}$ (ST-01, Ishihara Sangyo Kaisha), ${ }^{\mathrm{b}}$ other amines: secondary and tertiary amines, ${ }^{\mathrm{c}}$ conversion of amine (2a and 3a), which was calculated from the initial and final amounts of 2a and 3a, respectively.

Table S3. Gibbs free energy $\left(\Delta_{\mathrm{f}} \mathrm{G}^{\mathrm{o}}\right)$ of amines ${ }^{a}$

\begin{tabular}{clclc}
\hline entry & anti-Markovnikov products & $\Delta_{\mathrm{f}} \mathrm{G}^{\mathbf{0}} / \mathrm{kJmol}^{-1}$ & Markovnikov products & $\Delta_{\mathrm{f}} \mathrm{G}^{\mathbf{0}} / \mathrm{kJmol}^{-1}$ \\
\hline 1 & 4-phenyl-1-butanamine (2a) & 212.2 & 4-phenyl-2-butanamine (3a) & 209.7 \\
2 & 3-phenyl-1-propanamine (2b) & 203.8 & 1-phenyl-2-propanamine (3b) & 201.3 \\
3 & 2-phenylethanamine (2c) & 195.3 & 1-phenylethanamine (3c) & 192.9 \\
4 & Cyclohexanamine (2d) & 90.5 & - & 2-hexanamine (3e) \\
5 & 1-hexanamine (2e) & 66.1 & 2-octanamine (3f) & 63.7 \\
6 & 1-octanamine (2f) & 82.9 & 3-hexanamine (3i) & 80.5 \\
7 & 2-hexanamine (2i) & 63.7 & 63.7
\end{tabular}

${ }^{a}$ Data were calculated by the Joback method at the web site: https://www.chemeo.com/. 


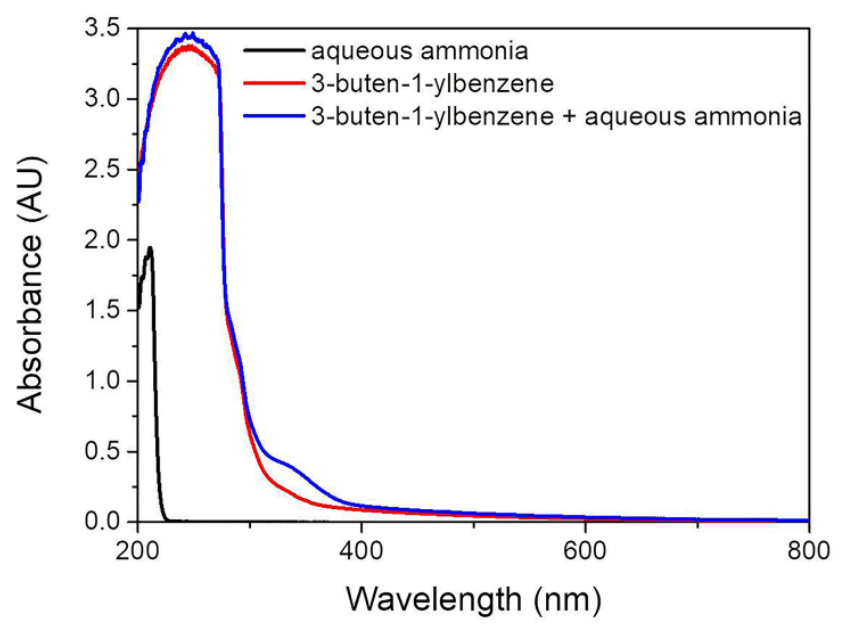

Figure S1. UV-visible spectra of 3-buten-1-ylbenzene, aqueous ammonia, and their mixture. Their concentrations in the solutions were $217.4 \mathrm{mmol} \mathrm{L}$ of 3-buten-1-ylbenze and $218.1 \mathrm{mmol} \mathrm{L}^{-1}$ of aqueous ammonia in $3 \mathrm{~mL}$ of acetonitrile.
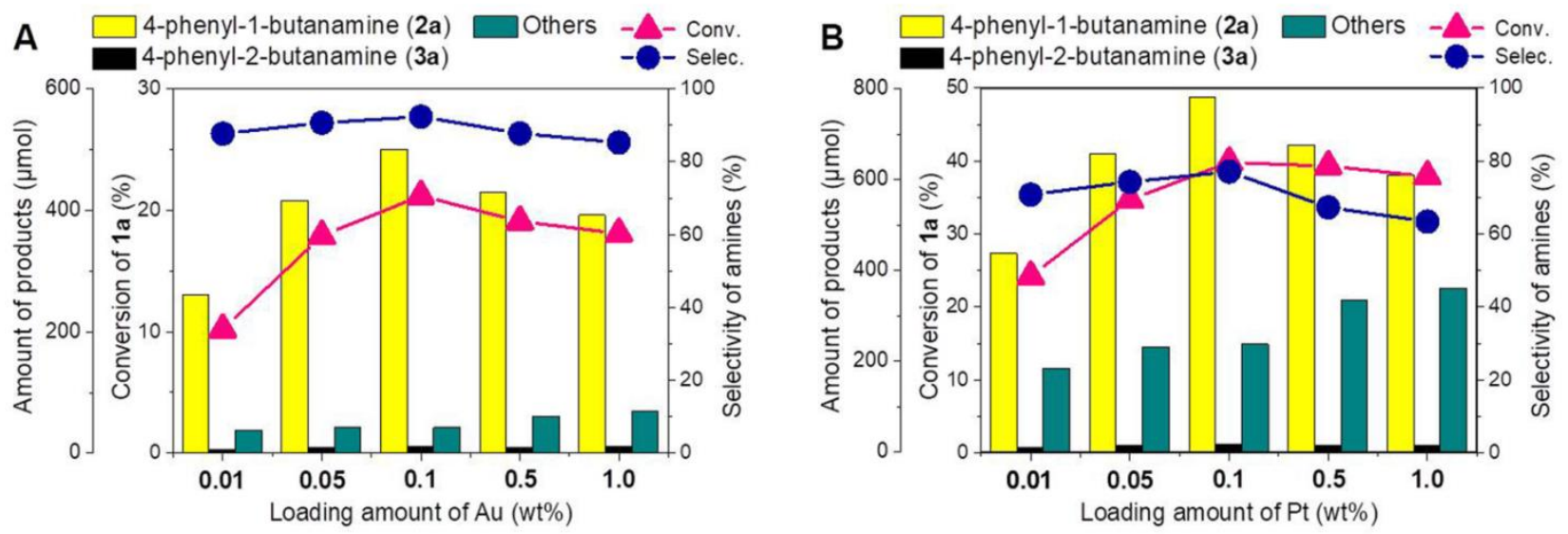

Figure S2. The results of the photocatalytic reaction tests, alkene conversion, amount of products, and selectivity to amine, with the (A) $\mathrm{Au}(x) / \mathrm{TiO}_{2}$ and $(\mathrm{B}) \mathrm{Pt}(x) / \mathrm{TiO}_{2}$ photocatalysts with various loading amount, $x$ wt.\%. Photocatalyst: $150 \mathrm{mg}$, reactants: 3-buten-1-ylbenzene $(0.4 \mathrm{~mL})$, aqueous ammonia $(1.6 \mathrm{~mL})$, solvent: acetonitrile $(4.0 \mathrm{~mL})$, wavelength: $\lambda \geq 300 \mathrm{~nm}$, light intensity: $40 \mathrm{~mW} \mathrm{~cm}^{-2}$ at $360 \pm 40 \mathrm{~nm}$ in wavelength, reaction time: $3 \mathrm{~h}$, reaction temperature: $303 \mathrm{~K}$. 


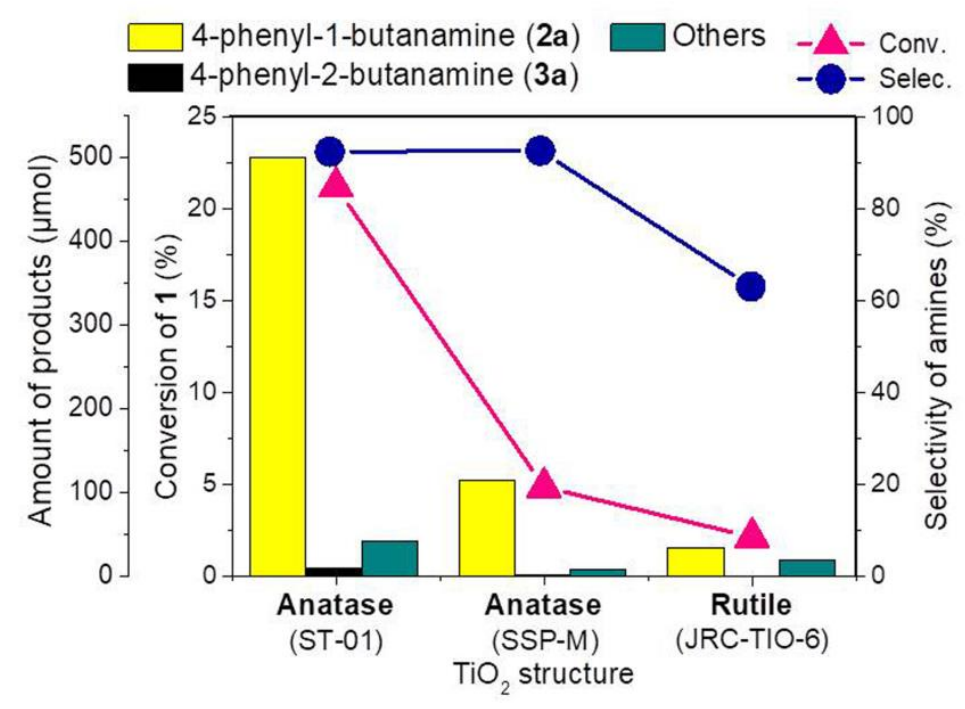

Figure S3. The results of alkene conversion, amount of products, and selectivity to amine with the $\mathrm{Au}(0.1) / \mathrm{TiO}_{2}$ photocatalysts of anatase and rutile. Photocatalyst: $150 \mathrm{mg}, \mathrm{Au}(0.1) / \mathrm{TiO}_{2}$, reactants: 3-buten-1-ylbenzene $(0.4 \mathrm{~mL})$ and aqueous ammonia (1.6 $\mathrm{mL}$ ), solvent: acetonitrile $(4.0 \mathrm{~mL})$, wavelength: $\lambda \geq 300 \mathrm{~nm}$, light intensity: $40 \mathrm{~mW} \mathrm{~cm}{ }^{-2}$ at $360 \pm 40 \mathrm{~nm}$ in wavelength, reaction time: $3 \mathrm{~h}$, reaction temperature: $303 \mathrm{~K}$.
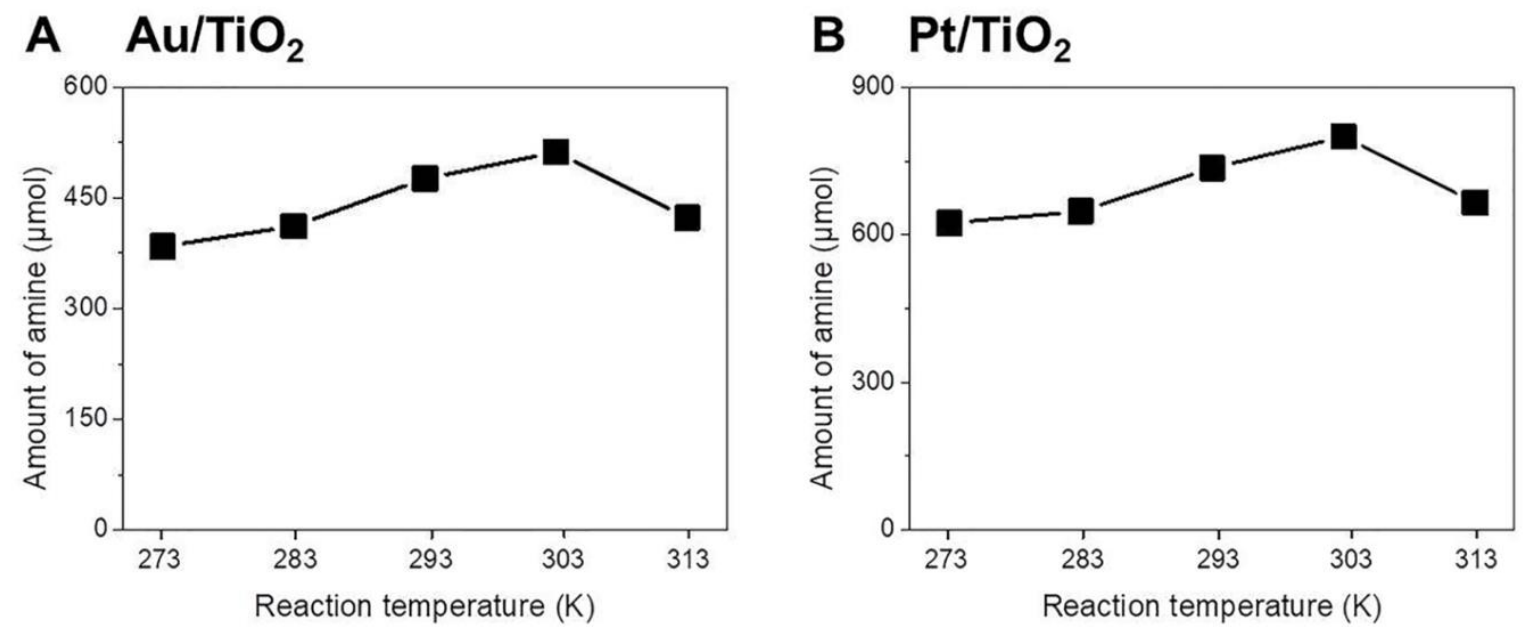

Figure S4. The amount of the amine obtained from 3-buten-1-ylbenzene (1a) in the photocatalytic reaction test at various

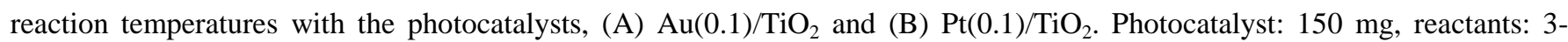
buten-1-ylbenzene $(0.4 \mathrm{~mL})$ and aqueous ammonia $(1.6 \mathrm{~mL})$, solvent: acetonitrile $(4.0 \mathrm{~mL})$, wavelength: $\lambda \geq 300 \mathrm{~nm}$, light intensity: $40 \mathrm{~mW} \mathrm{~cm}^{-2}$ at $360 \pm 40 \mathrm{~nm}$ in wavelength, reaction time: $3 \mathrm{~h}$. 

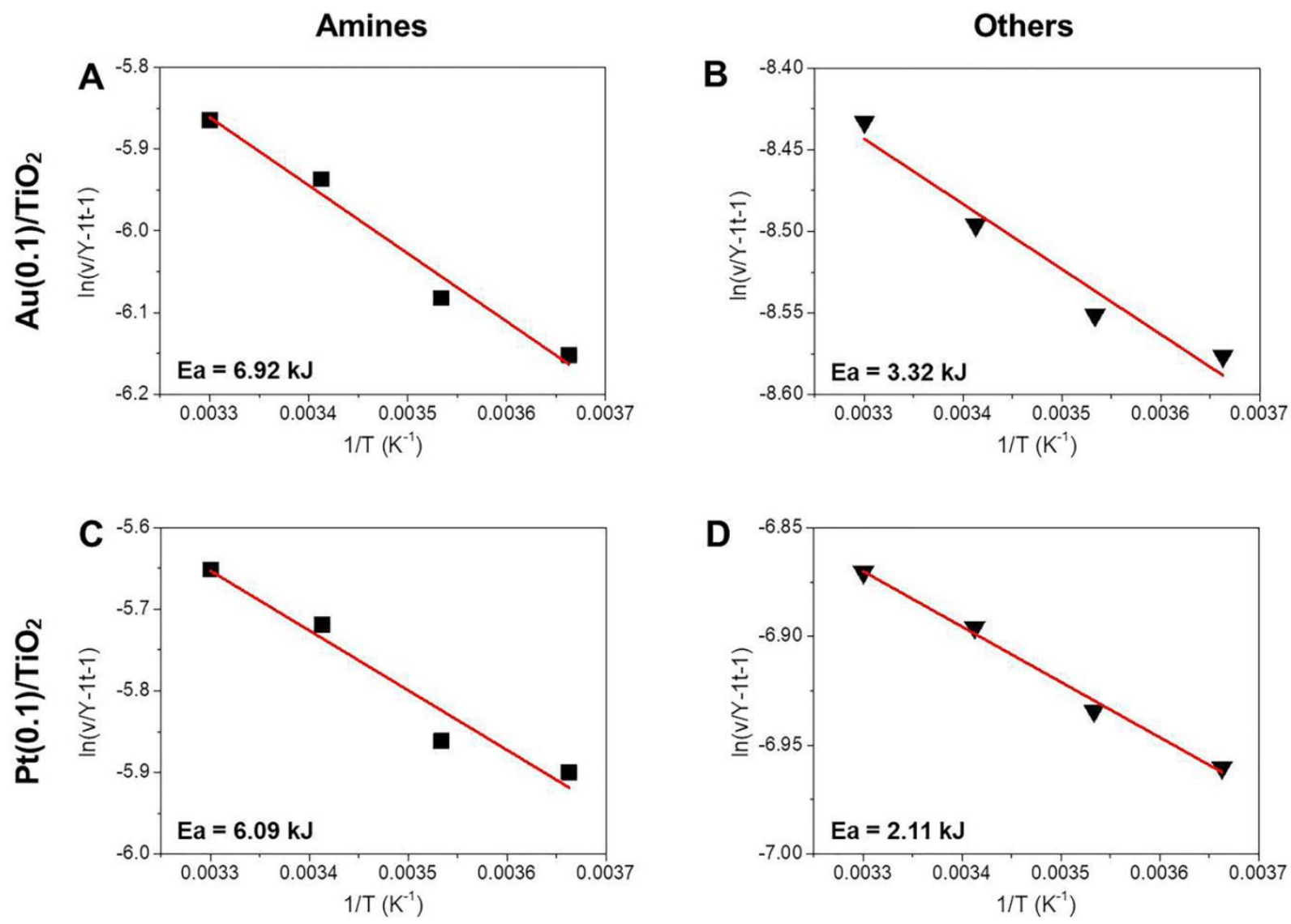

Figure S5. The pseudo-Arrhenius plots of the production rates in the photocatalytic reaction tests for hydroamination (A, B) with the $\mathrm{Au}(0.1) / \mathrm{TiO}_{2}$ photocatalyst, and $(\mathrm{C}, \mathrm{D})$ with the $\mathrm{Pt}(0.1) / \mathrm{TiO}_{2}$ photocatalyst (A, C: amines, $\mathrm{B}, \mathrm{D}$ : other products). 


\section{NMR Analysis}

${ }^{1} \mathrm{H}$ and ${ }^{13} \mathrm{C}$ NMR spectra were recorded using at ambient temperature on JEOL ECS-400 operating at $500 \mathrm{MHz}$. Abbreviations used in the NMR experiments: s, singlet; d, doublet; t, triplet; q, quantet.
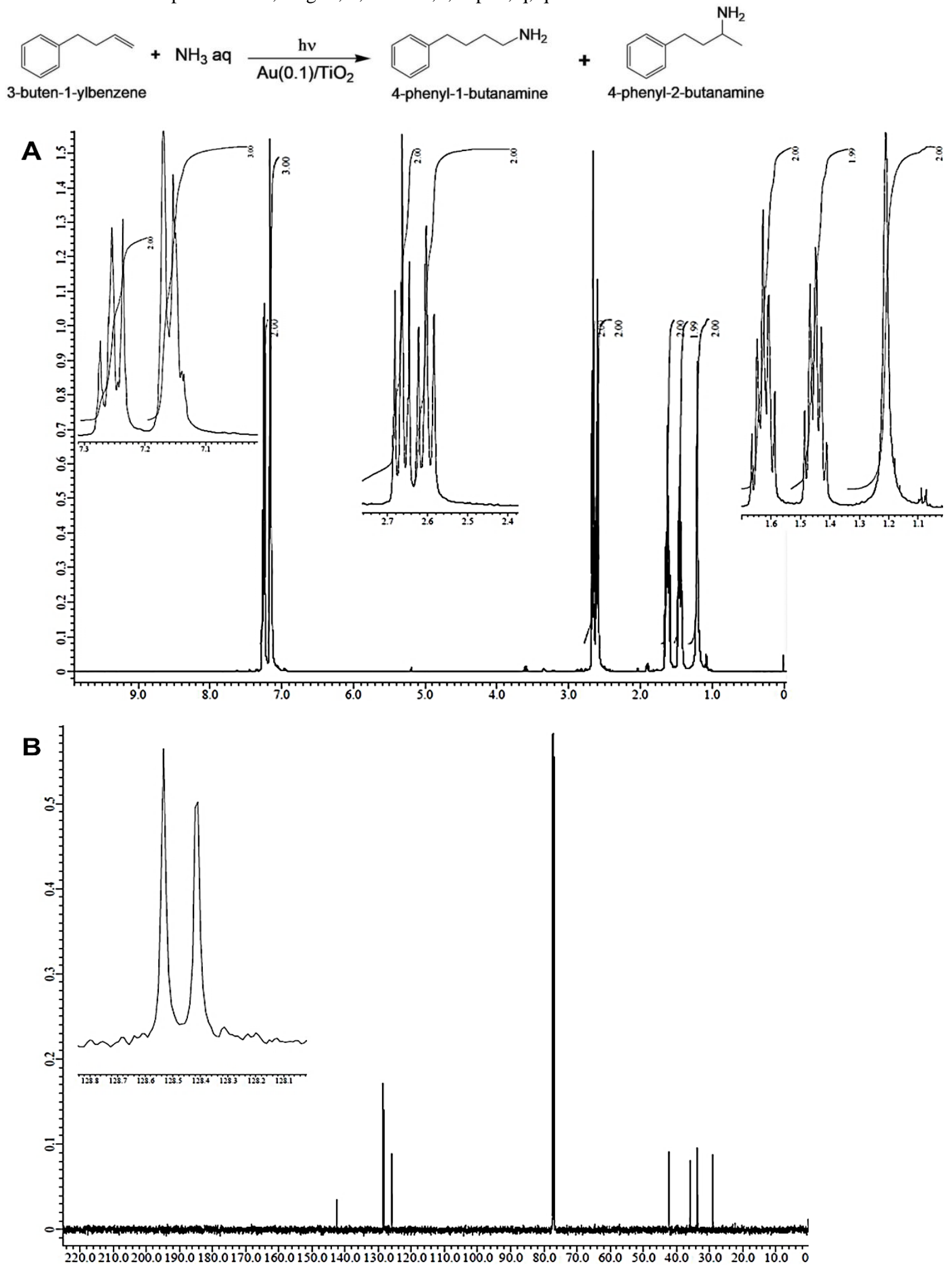

Figure S6. NMR data results of the photocatalytic reaction test for the hydroamination of 3-buten-1-ylbenzene by ammonia solution with the $\mathrm{Au}(0.1) / \mathrm{TiO}_{2}$ sample, (A) ${ }^{1} \mathrm{H}-\mathrm{NMR}$ data, and (B) ${ }^{13} \mathrm{C}-\mathrm{NMR}$ data. Yield: yellow oil, $346.3 \mathrm{mg}$, isolated yield; $88.9 \%$. ${ }^{1} \mathrm{H}-\mathrm{NMR}$ in $\mathrm{CDCl}_{3}(\delta, \mathrm{ppm}): 7.27-7.15(\mathrm{~m}, 5 \mathrm{H}), 2.66(\mathrm{t}, \mathrm{J}=6.8 \mathrm{~Hz}, 2 \mathrm{H}), 2.60(\mathrm{t}, \mathrm{J}=7.6 \mathrm{~Hz}, 2 \mathrm{H}), 1.63(\mathrm{q}, \mathrm{J}=7.8 \mathrm{~Hz}$, $2 \mathrm{H}), 1.45(\mathrm{q}, \mathrm{J}=7.3 \mathrm{~Hz}, 2 \mathrm{H}), 1.21(\mathrm{~s}, 2 \mathrm{H})$. Some small peaks other than expected in the spectrum may be resulting from the ethyl alcohol and 1-methyl-3-phenylpropylamine (3a). ${ }^{13} \mathrm{C}-\mathrm{NMR}$ in $\mathrm{CDCl}_{3}(\delta, \mathrm{ppm}): 142.6,128.5,128.4,125.8,42.3,35.9$, 33.6, 28.9. 

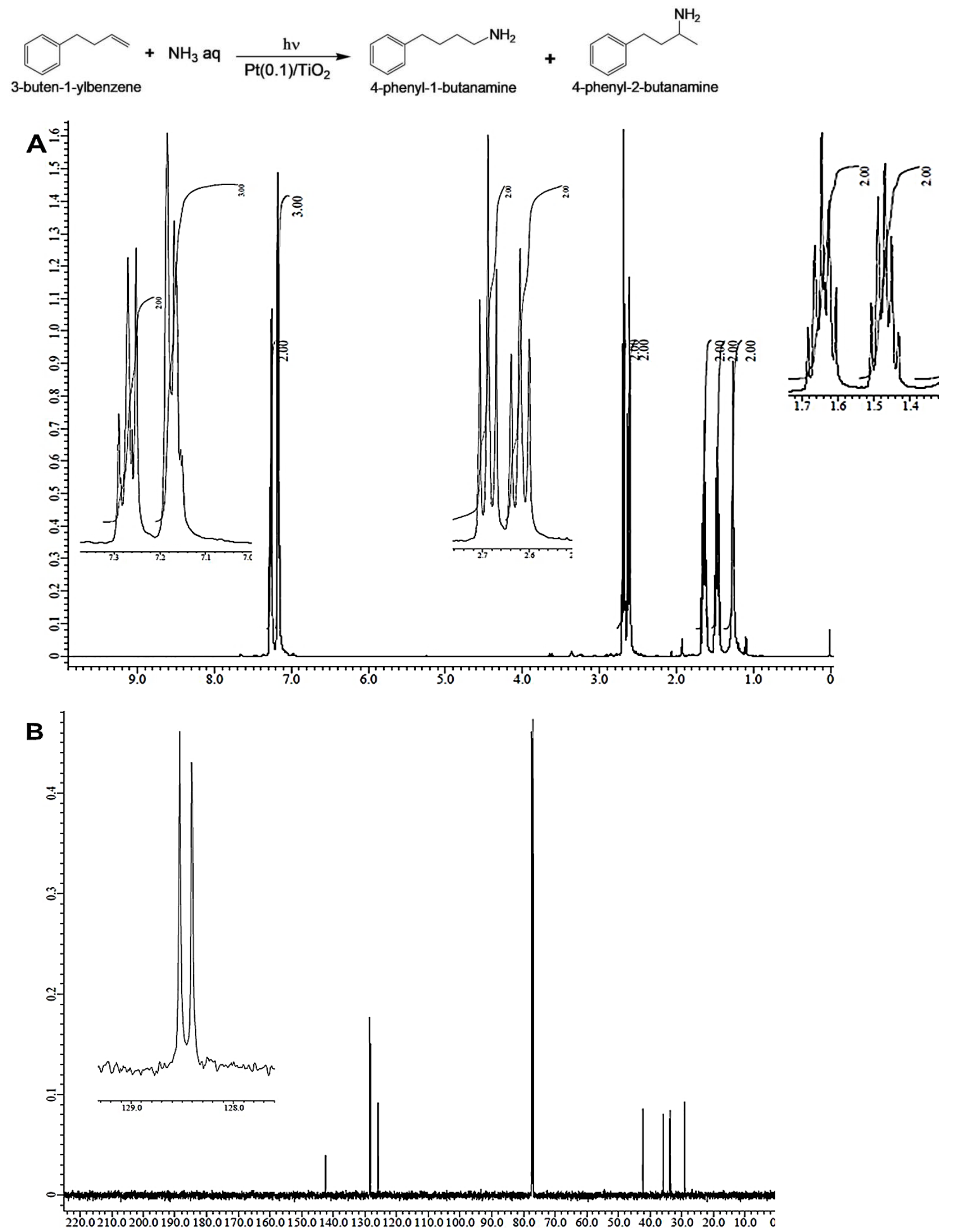

Figure S7. NMR data results of photocatalytic hydroamination by $\mathrm{Pt}(0.1) / \mathrm{TiO}_{2}$. (A) ${ }^{1} \mathrm{H}-\mathrm{NMR}$ data, and $(\mathrm{B}){ }^{13} \mathrm{C}-\mathrm{NMR}$ data. Yield: yellow oil, $284.0 \mathrm{mg}$, isolated yield; $72.9 \%$. ${ }^{1} \mathrm{H}-\mathrm{NMR}$ in $\mathrm{CDCl}_{3}(\delta, \mathrm{ppm}): 7.29-7.16(\mathrm{~m}, 5 \mathrm{H}), 2.69(\mathrm{t}, \mathrm{J}=6.9 \mathrm{~Hz}, 2 \mathrm{H})$, $2.62(\mathrm{t}, \mathrm{J}=7.8 \mathrm{~Hz}, 2 \mathrm{H}), 1.65(\mathrm{q}, \mathrm{J}=7.8 \mathrm{~Hz}, 2 \mathrm{H}), 1.47(\mathrm{q}, \mathrm{J}=7.6 \mathrm{~Hz}, 2 \mathrm{H}), 1.27(\mathrm{~s}, 2 \mathrm{H})$. Some small peaks other than expected in the spectrum may be resulting from the ethyl alcohol and 1-methyl-3-phenylpropylamine (3a). ${ }^{13} \mathrm{C}-\mathrm{NMR}$ in $\mathrm{CDCl}{ }_{3}(\delta, \mathrm{ppm})$ : $142.6,128.5,128.4,125.8,42.3,35.9,33.6,28.9$. 